\title{
PENGUJIAN KEMAMPUAN ADSORPSI DARI ADSORBEN KARBON AKTIF UNTUK MESIN PENDINGIN TENAGA SURYA
}

\author{
Bonardo S. ${ }^{1}$, Himsar Ambarita ${ }^{2}$, Tulus B. Sitorus ${ }^{3}$, Dian M. Nasution4, Syahril Gultom ${ }^{5}$ \\ 1,2,3,4,5 Departemen Teknik Mesin Fakultas Teknik, Universitas Sumatera Utara \\ E-mail : siregar_bonardo@yahoo.co.id
}

\begin{abstract}
ABSTRAK
Akhir-akhir ini mesin pendingin siklus adsorpsi semakin banyak diteliti oleh para ahli karena disamping ekonomis juga ramah lingkungan dan menggunakan energy terbarukan yaitu energi surya. Agar proses adsorpsi dan desorpsi mesin pendingin adsorpsi dapat berjalan dengan baik perlu diketahui jumlah perbandingan yang ideal antara adsorben dengan refrigeran yang digunakan. Disini untuk mencari perbandingan antara absorben karbon aktif menggunakan baut maupun tidak menggunakan baut. Data tersebut dapat dicari menggunakan alat penguji kapasitas adsorpsi. Alat penguji kapasitas adsorpsi yang digunakan dilengkapi dengan lampu halogen $1000 \mathrm{~W}$ sebagai sumber panas. Adsorber pada alat penguji ini terbuat dari bahan stainless steel yang bertujuan agar tahan terhadap korosi akibat dari refrigeran yang digunakan. karbon aktif yang digunakan sebagai adsorben sebanyak $1 \mathrm{~kg}$. Sedangkan refrigeran yang digunakan yaitu metanol. Kapasitas metanol yang dapat diadsorpsi dan didesorpsi oleh adsorben karbon aktif mengunakan baut adalah sebanyak $350 \mathrm{~mL}$. Sedangkan kapasitas metanol yang dapat diadsorpsi dan didesorpsi oleh adsorben karbon aktif tidak menggunakan baut adalah sebanyak $275 \mathrm{~mL}$.
\end{abstract}

Kata kunci: Adsorpsi, desorpsi, adsorber, karbon aktif, refrigeran

\section{PENDAHULUAN}

Dalam pengujian sebuah alat pendingin dapat kita ketahui bahwa sistem pendingin adalah untuk mengembalikan gas menjadi cairan dan selanjutnya kembali menguap menjadi gas. Dalam bidang teknik, istilah pendinginan harus dibayangkan lebih dari sekedar pendingin atau menjaga sesuatu tetap dingin, melainkan semua teknik yang dapat digunakan untuk menurunkan temperatur suatu medium sampai lebih rendah daripada temperatur lingkungannya (Ambarita,2012).

Proses pendinginan merupakan suatu usaha untuk menurunkan suhu pada ruangan ataupun pada suatu material, dengan kata lain mendapatkan kondisi yang diinginkan oleh produk atau material, dalam hal ini temperatur yang rendah agar produk atau material dapat disimpan dalam waktu yang relatif lama, baik untuk konsumsi, produksi, maupun perdagangan. Penyimpanan dan transportasi bahan pangan, proses pengolahan makanan dan minuman, pembuatan es (ice making) merupakan beberapa contoh kegiatan yang memerlukan proses pendinginan dan pembekuan. Proses pendinginan merupakan proses pengambilan kalor / panas suatu ruang atau benda untuk menurunkan suhunya dengan jalan memindahkan kalor yang terkandung dalam ruangan atau benda tersebut. Sehingga proses pendinginan merupakan rangkaian proses pindah panas. Proses pindah panas dapat terjadi secara konveksi, konduksi maupun radiasi. 
Salah satu opsi yang cukup potensial memanfaatan energi surya termal adalah untuk menggerakkan siklus adsorpsi untuk daerah-daerah yang tidak mempunyai aliran listrik. Sementara banyak desa-desa di Indonesia yang sangat membutuhkan mesin pendingin (refrigerasi) untuk membantu aktivitas ekonomi. Misalnya untuk pengawetan dan pembuatan makanan, atau untuk penyimpanan vaksin dan lain-lain. Oleh karena itu mesin pendingin yang dapat digerakkan tenaga surya dan tidak memerlukan listrik sangat dibutuhkan terutama untuk daerah-daerah pedesaan di Indonesia.

\section{TINJAUAN PUSTAKA Siklus Adsorpsi}

Siklus adsorpsi adalah siklus termodinamika yang dapat digunakan untuk menghasilkan efek pendinginan, siklus ini menggunakan panas sebagai sumber energi utama untuk menghasilkan efek pendinginan (Ambarita, 2013).

\section{Adsorben}

Pada adsorben berpori mikro seperti karbon aktif, salah satu teori yang paling sering digunakan untuk memberi gambaran adsorpsi fisik molekul gas adalah teori pengisian volume pori mikro (TVFM, Theory Of Volume Filling of Micropores) yang dikembangkan oleh M.M Dubinin. Berbeda dengan teori - teori sebelumnya yang memberikan gambaran fisik berupa pembentukan satu atau lebih lapisan (film) adsorpsi pada permukaan adsorben. Teori pengisian volume mikro menekankan bahwa adsorpsi tidak terjadi melalui pembentukan lapisan (film) adsorpsi tetapi berupa pengisian volume dalam ruang adsorpsi dan zat yang teradsorpsi berada dalam bentuk cair (Wuntu dan Kamu, 2008).

Persamaan adsorpsi dapat dilihat dibawah ini :

$$
\mathrm{W}=\mathrm{W}_{0} \exp \left[-\left(A /\left(E_{0}\right)^{n}\right]\right.
$$

Dengan $\mathrm{W}$ adalah Volume adsorbat yang terkondensasi pada suhu (T) dan tekanan Relative $\left(\mathrm{P} / \mathrm{P}_{0}\right)\left(\mathrm{cm}^{3} / \mathrm{gr}\right)$, $\mathrm{T}$ adalah suhu mutlak $(\mathrm{K}), \mathrm{P}$ adalah tekanan parsial adsorbat $(\mathrm{atm})$, $\mathrm{P}_{0}$ adalah tekanan uap jenuh adsorbat $(\mathrm{atm}), \mathrm{W}_{0}$ adalah volume total pori mikro yang dapat diakses oleh adsorbat $\left(\mathrm{cm}^{3} / \mathrm{gr}\right)$, A adalah kemampuan adsorpsi dari karbon aktif, $\mathrm{E}_{0}$ merupakan Energy adsorpsi (J/mole), $\mathrm{n}$ adalah parameter yang bergantung pada jenis adsorbat.

Dalam persamaan ini, parameter n pada persamaan Dubinin - Astakhov ditetapkan memiliki nilai 2 sehingga persamaan Dubinin - Astakhov dinyatakan dalam bentuk :

$$
\mathrm{W}=\mathrm{W}_{0} \exp \left[-\left(A /\left(E_{0}\right)^{2}\right]\right.
$$

Persamaan (2) selanjutnya dapat diubah ke dalam bentuk :

$$
\operatorname{Ln} \mathrm{W}=\mathrm{LnW}_{0}-\left(1 /\left(\mathrm{E}_{0}\right)^{2} \mathrm{~A}^{2}\right.
$$




\section{Refrigeran}

Refrigeran adalah fluida kerja utama pada suatu siklus pendingin (refrigerasi) yang berfungsi menyerap panas pada temperature dan tekanan rendah dan membuang panas pada temperature dan tekanan tinggi.

\section{Kalor (Q)}

Kalor adalah energi yang berpindah yang mengakibatkan perubahan temperatur (Holman, 1984).

\section{Kalor Laten}

$$
Q_{L}=L_{e} m
$$

dengan $\mathrm{Q}_{\mathrm{L}}$ adalah Kalor laten (J), Le adalah kapasitas kalor spesifik laten $(\mathrm{J} / \mathrm{kg}), m$ adalah massa zat $(\mathrm{kg})$.

\section{Kalor Sensibel}

Kalor sensibel adalah kalor yang diberikan atau yang dilepaskan oleh suatu jenis fluida sehingga temperaturnya naik atau turun tanpa menyebabkan perubahan fasa fluida tersebut (Holaman, 1984).

$$
Q_{s}=m C_{p} \Delta T
$$

\section{Perpindahan Panas}

Panas hanya akan berpindah jika ada perbedaan temperatur, yaitu dari sistem yang bertemperatur tinggi ke sistem bertemperatur rendah.

\section{Konduksi}

Perpindahan panas di sini terjadi akibat interaksi antara partikel tanpa diikuti perpindahan partikelnya (Ambarita, 2011).

$$
Q_{c}=k A \frac{\Delta T}{\Delta x}
$$

\section{Konveksi}

Perpindahan panas konveksi adalah perpindahan panas antara permukaan padat yang berbatasan dengan fluida mengalir.

$$
Q_{h}=h A\left(T_{s}-T_{L}\right)
$$

\section{Radiasi}

Perpindahan panas radiasi adalah panas yang dipindahkan dengan cara memancarkangelombang elektromagnetik.

$$
Q_{h}=h A\left(T_{s^{-}} T_{L}\right)
$$




\section{METODOLOGI PENELITIAN}

\section{Tempat dan Waktu}

Tempat penelitian adalah laboratorium Teknik Pendingin, gedung Fakultas Teknik USU. Waktu pelaksanaan penelitian \pm 6 bulan.

\section{Bahan}

Pada penelitian ini, bahan pengujian yang digunakan adalah sebagai berikut.

1. Adsorben karbon aktif

2. Refrigeran

\section{Alat Ukur yang Digunakan pada Pengujian Kapasitas Adsorpsi}

Alat-alat ukur yang digunakan pada pengujian kapasitas adsorpsi ini adalah sebagai berikut.

1. Pace XR5 Data Logger

2. Thermokopel

3. Sensor Tekanan

\section{Peralatan yang Digunakan}

1. Pompa Vakum

2. Katup

3. Pipa Penghubung

4. Selang Karet

5. Baut

6. Kotak Isolasi gelas ukur

\section{Prosedur Pengujian}

Prosedur pengujian dapat diuraikan sebagai berikut ini.

1. Proses assembling/penyambungan alat penguji kapasitas adsorpsi. Komponen adsorber dengan gelas ukur dirangkai/dihubungkan dengan baik. Pada persambungan pipa dilem dengan baik dan kuat untuk menghindari kebocoran.

2. Kemudian dipasang termokopel dan sensor tekanan. Pemasanangan termokopel pada adsorber (4 titik) dan pada gelas ukur (3 titik). Setelah terpasang dengan baik, termokopel dan sensor tekanan kemudian dihubungkan ke terminal (port) Pace XR5 data logger .

3. Adsorber dipanaskan selama 7 jam (mulai pukul 13.05 WIB sampai dengan pukul 20.05 WIB).

4. Kemudian pada pukul 20.05 WIB dilakukan pemvakuman dengan mengunakan pompa vakum untuk mengeluarkan gas/udara dan air/uap air yang terdapat pada adsorben karbon aktif. Setelah kondisi vakum, kemudian semua katup ditutup.

5. Pada gelas ukur diisi refrigeran. Pengujian mengunakan metanol dengan adsorber menggunakan baut, pengujian kedua menggunakan adsorber tanpa baut. Kemudian lampu alat penguji kapasitas adsorpsi dimatikan. Data tekanan, temperatur adsorber dan gelas ukur akan otomatis tersimpan pada Pace XR5 Data Logger dalam bentuk Notepad yang kemudian dapat di transfer dalam bentuk grafik dan dalam bentuk microsoft $\mathrm{xl}$. 
6. Kemudian gelas ukur dimasukkan ke dalam kotak styrofoam dan pada styrofoam diisi es sebanyak $5 \mathrm{~kg}$. Hal ini bertujuan untuk melihat berapa refrigeran yang dapat diserap oleh karbon aktif dengan kondisi bagian luarnya sudah menjadi es. Karena gelas ukur nantinya akan digantikan fungsinya oleh evaporator pada mesin pendingin siklus adsorpsi tenaga surya.

7. Katup antara adsorber dan gelas ukur dibuka untuk memulai proses adsorpsi (pukul 20.05 WIB sampai keesokan harinya pukul 13.05 WIB). Temperatur adsorber dan tekanan akan turun seiring dengan turunnya temperatur lingkungan. Pada malam hari dengan turunya temperatur adsorber, maka karbon aktif akan menyerap refrigeran sehingga refrigeran akan menguap dan naik ke adsorben karbon aktif.

8. Proses desorpsi mulai pukul 13.05 WIB sampai dengan pukul 20.05 WIB dengan menyalakkan lampu pemanas alat penguji kapasitas adsorpsi $(1000 \mathrm{~W})$. Seiring dengan naiknya temperatur adsorber maka refrigeran akan menguap dari adsorben karbon aktif dan masuk ke gelas ukur dalam fasa cair.

\section{HASIL PENGUJIAN \\ Data Pemanasan Awal Alat Penguji Kapasitas Adsorpsi Adsorber Menggunakan Baut}

Pengujian kapasitas refrigeran metanol yang teradsorpsi. Pada pengujian ini adsorber di kenakan baut dan tanpa dikenakan baut dengan gelas ukur diisolasi. Adsorber mulai dipanaskan mulai pukul 13.05 WIB sampai dengan pukul 20.05 WIB dengan mengunakan lampu pemanas alat uji kapasitas adsorpsi. Kemudian pada pukul 20.05 WIB dilakukan pemvakuman alat pengujian kapasitas adsorpsi dengan menggunakan pompa vakum. Pemvakuman dilakukan untuk mengeluarkan partikel-partikel pengotor dan uap air. Perhatikan gambar grafik berikut.

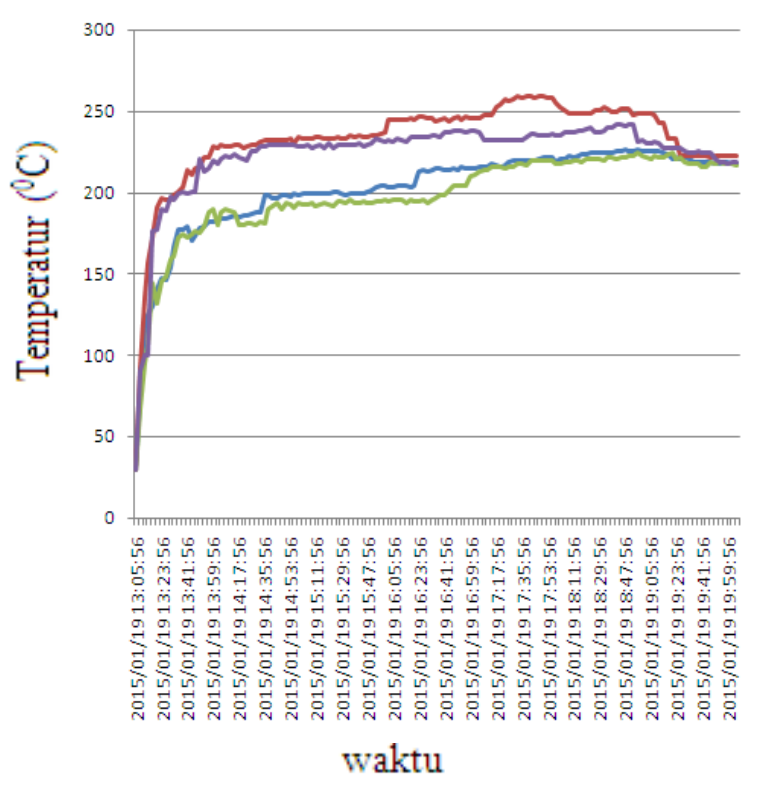

Gambar 4.1 Grafik Temperatur vs Waktu Pemanasan Awal Alat Penguji Adsorpsi (metanol) menggunakan baut. 
Temperatur awal percobaan pada adsorber adalah $29,50^{\circ} \mathrm{C}$ pada pukul 13.05 WIB. Temperatur maksimum adsorber yang dapat dicapai ketika pemanasan adalah $259,3^{\circ} \mathrm{C}$ yaitu berada titik 3 thermocouple pada pukul $17.50 \mathrm{WIB}$.

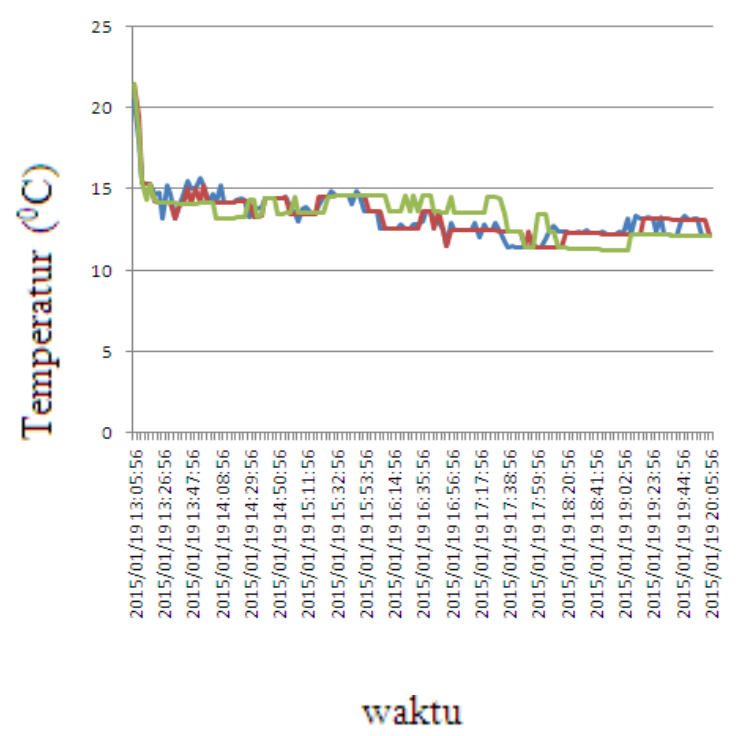

Gambar 4.2 Grafik Temperatur gelas ukur vs Waktu Pada Saat Pemanasan Awal

Temperatur terendah yang dapat dicapai pada gelas ukur yaitu $11,2^{\circ} \mathrm{C}$ pada pukul 18.47 WIB.

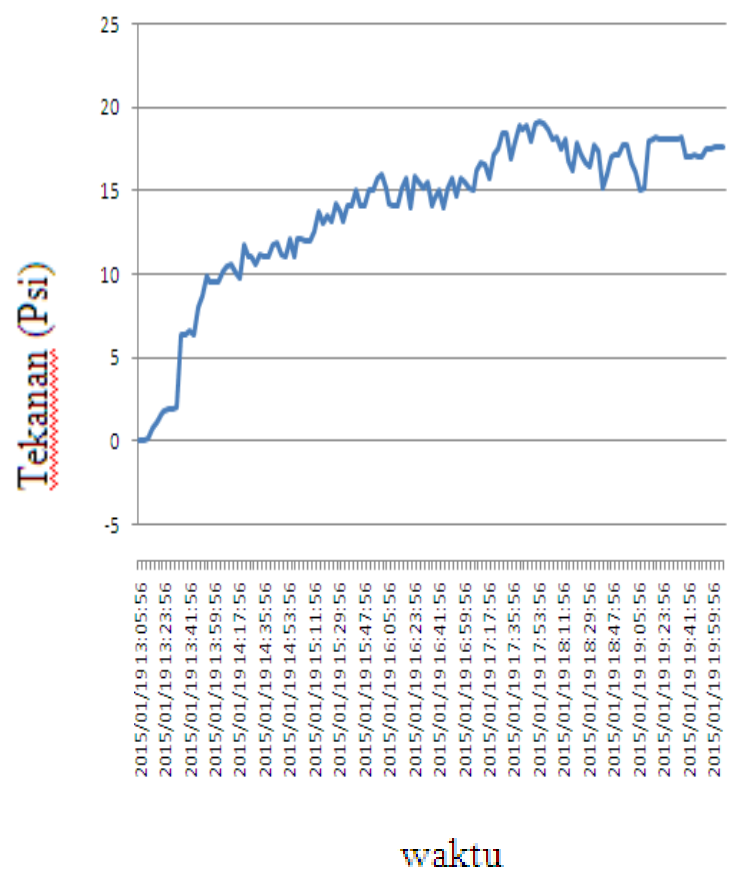

Gambar 4.3 Grafik Tekana vs Waktu

Tekanan maximum yang dapat dicapai pada porses pemanasan awal yaitu 19,53 Psi pada pukul 17.53 WIB. 


\section{Adsorber Tidak Menggunakan Baut}

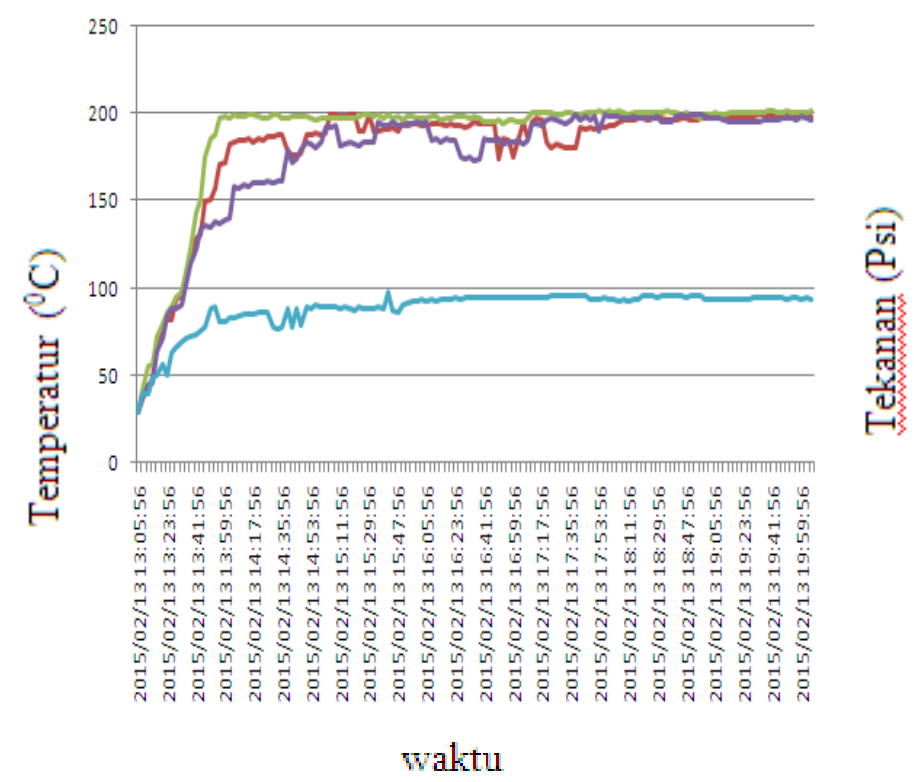

Gambar 4.4 Grafik Temperatur vs Waktu Pemanasan Awal Alat Penguji Adsorpsi (metanol) Tidak mengunakan baut

Temperatur awal percobaan pada adsorber adalah $29,50^{\circ} \mathrm{C}$ pada pukul 13.05 WIB. Temperatur maksimum adsorber yang dapat dicapai ketika pemanasan adalah $201,9^{\circ} \mathrm{C}$ yaitu berada titik 3 thermocouple pada pukul 19.38. WIB.

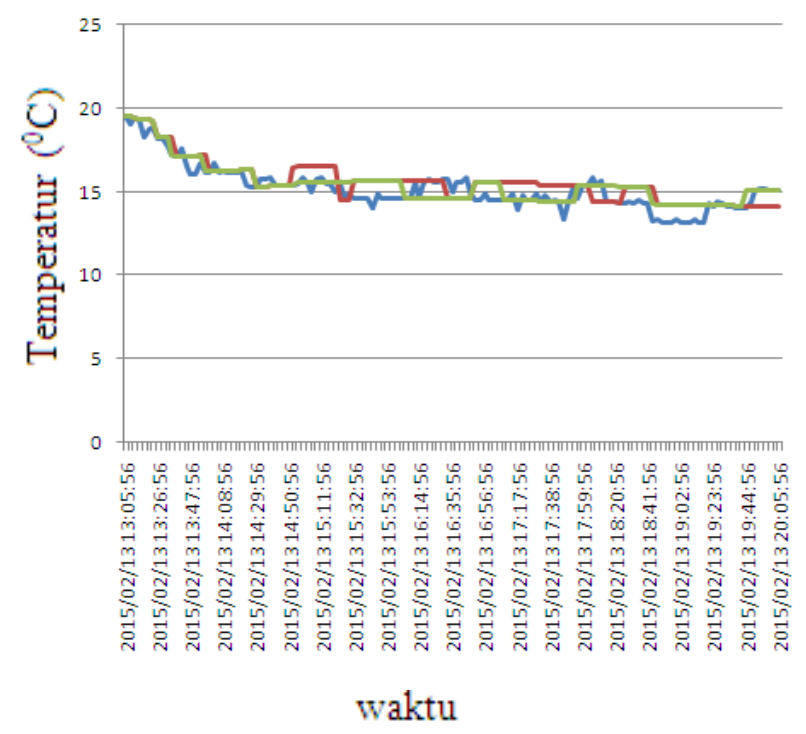

Gambar 4.5 Grafik Temperatur gelas ukur vs Waktu Pada Saat Pemanasan Awal Temperatur terendah yang dapat dicapai pada gelas ukur yaitu $13,2^{\circ} \mathrm{C}$ pada pukul 18.50 WIB. 


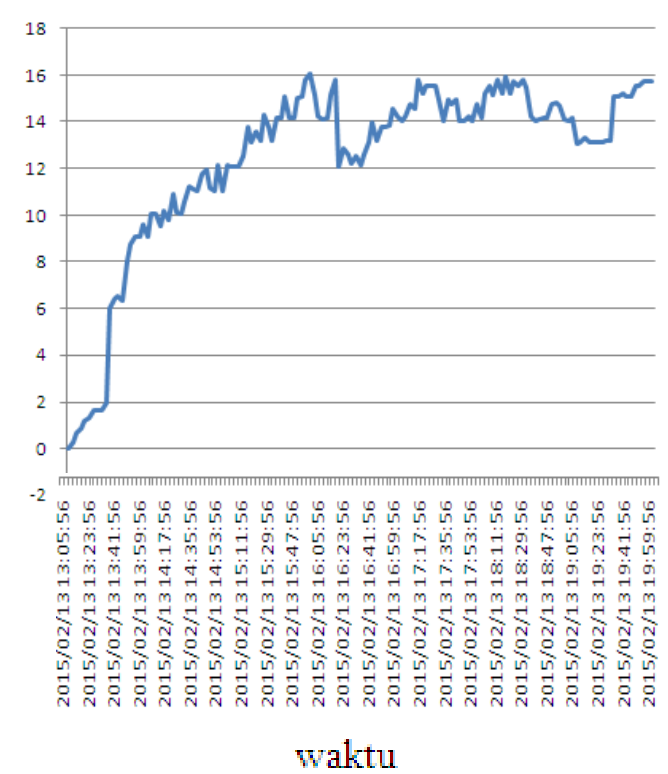

Gambar 4.6 Grafik Tekana vs Waktu

Tekanan maximum yang dapat dicapai pada porses pemanasan awal yaitu 16,04 Psi pada pukul 15.59 WIB.

\section{Data Pengujian Adsorpsi Metanol}

Adsorpsi dimulai pada pukul 20.08 WIB setelah selesai proses pemanasan dan pemvakuman dan selasai pada pukul 13.02 WIB. Pada pengujian ini gelas ukur diisolasi, sehingga temperatur lingkungan tidak berpengaruh terhadap gelas ukur.

\section{Adsorber Menggunakan Baut}

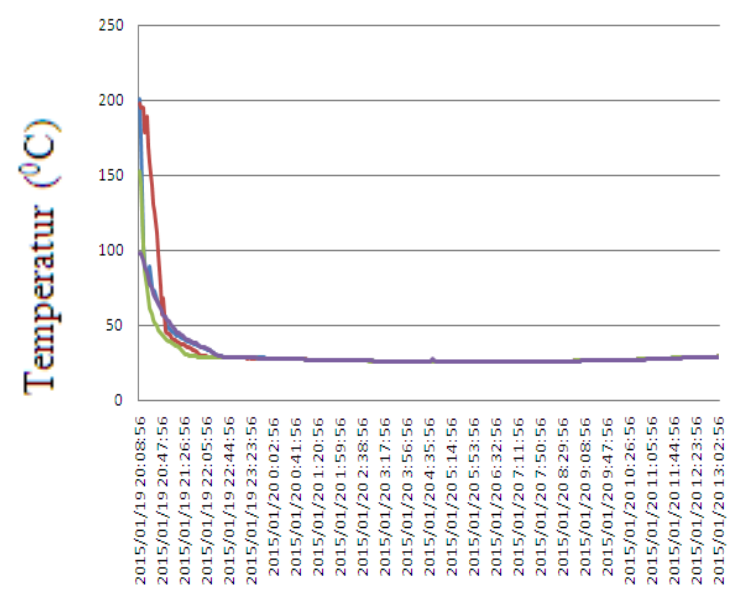

waktu 


\section{Gambar 4.7 Grafik Temperatur vs Waktu Adsorpsi Alat Penguji Adsorpsi (metanol) menggunakan baut}

Temperatur terendah yang dapat dicapai pada adsorber terjadi yaitu $26^{\circ} \mathrm{C}$ pada pukul 06.32 WIB.

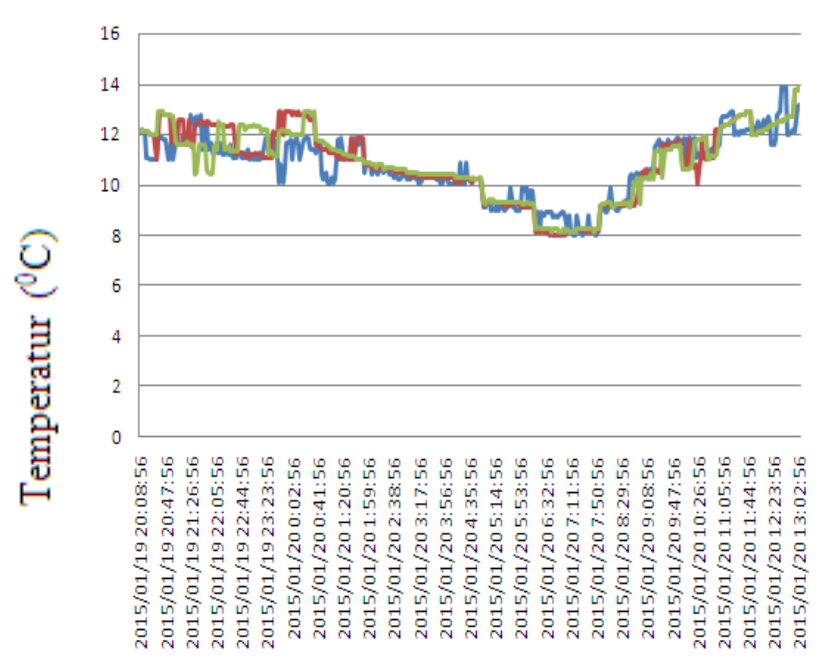

waktu

Gambar 4.8 Grafik Temperatur vs Waktu Adsorpsi Gelas Ukur Refrigerant (metanol) Temperatur terendah yang dapat dicapai pada gelas ukur yaitu $8^{\circ} \mathrm{C}$ pada pukul 07.14 WIB.

Pada proses adsorpsi ini, volume refrigeran metanol yang mampu diserap oleh karbon aktif $1 \mathrm{~kg}$ beserta baut adalah sebanyak $350 \mathrm{~mL}$.

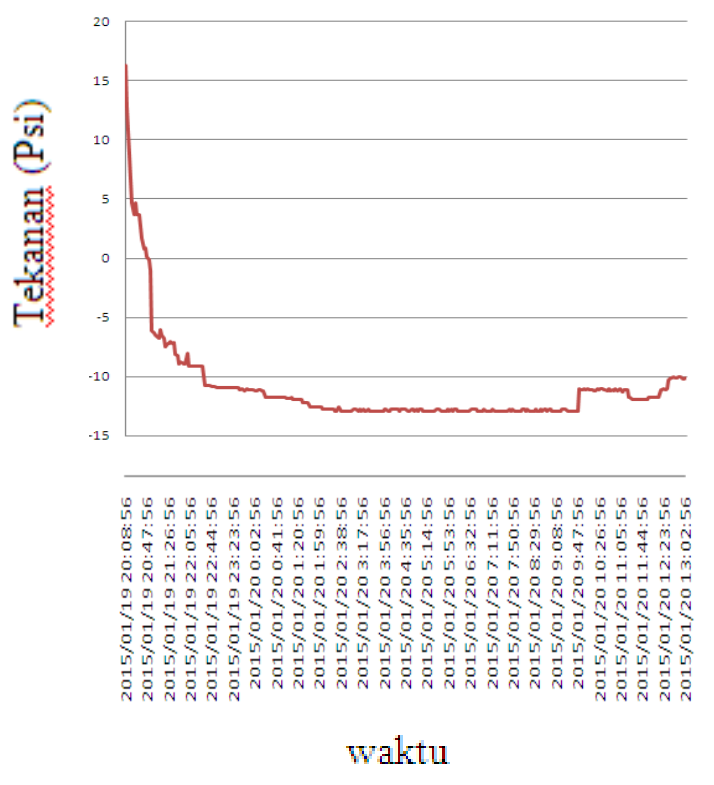

Gambar 4.9 Grafik Tekana vs Waktu 
Tekanan minimum yang dapat dicapai pada porses adsorpsi yaitu -12,95 Psi pada pukul 02.23 WIB.

\section{Adsorber Tanpa Menggunakan Baut}

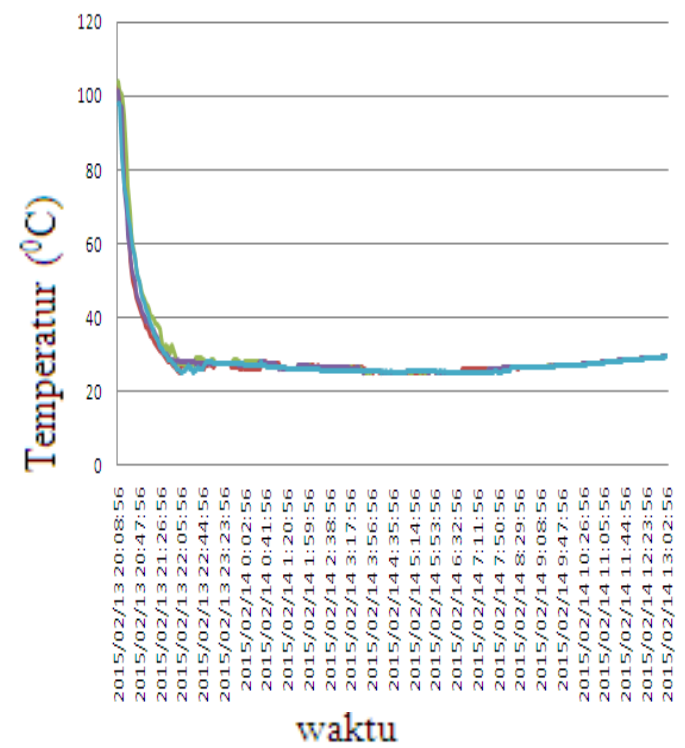

Gambar 4.10 Grafik Temperatur vs Waktu Adsorpsi Alat Penguji Adsorpsi (metanol) tanpa baut.

WIB.

Temperatur terendah yang dapat dicapai pada adsorber yaitu $25^{\circ} \mathrm{C}$ pada pukul 06.29

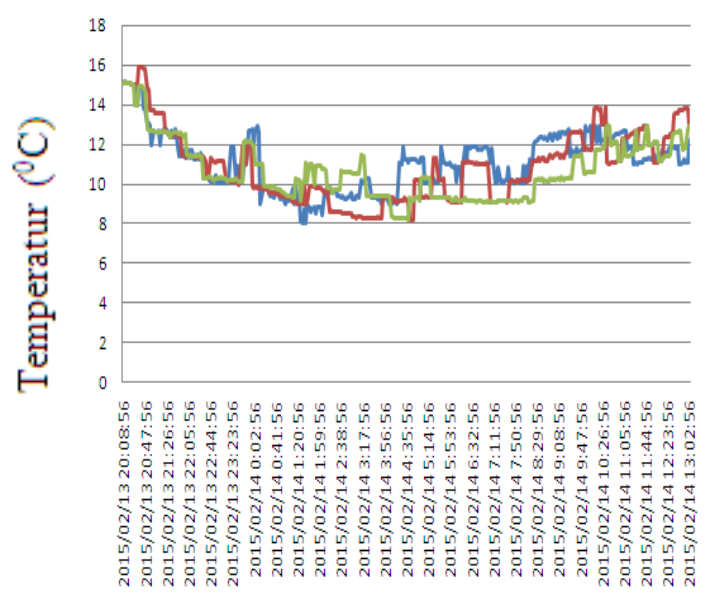

waktu

Gambar 4.11 Grafik Temperatur vs Waktu Adsorpsi Gelas Ukur Refrigerant (metanol)

Temperatur terendah yang dapat dicapai pada gelas ukur yaitu $8^{\circ} \mathrm{C}$ pada pukul 01.29. 
Pada proses adsorpsi ini, volume refrigeran metanol yang mampu diserap oleh karbon aktif $1 \mathrm{~kg}$ tanpa baut adalah sebanyak $275 \mathrm{~mL}$.

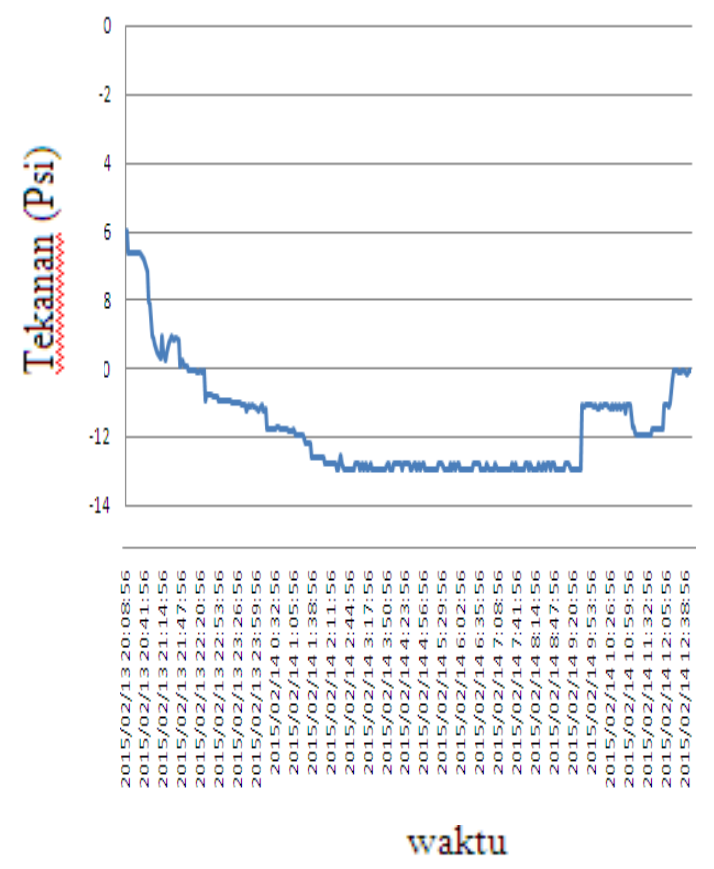

Gambar 4.12 Grafik Tekana vs Waktu

Tekanan minimum yang dapat dicapai pada porses yaitu $-12,95$ Psi pada pukul 02.38 WIB.

\section{Data Pengujian Desorpsi Metanol}

\section{Adsorber Menggunakan Baut}

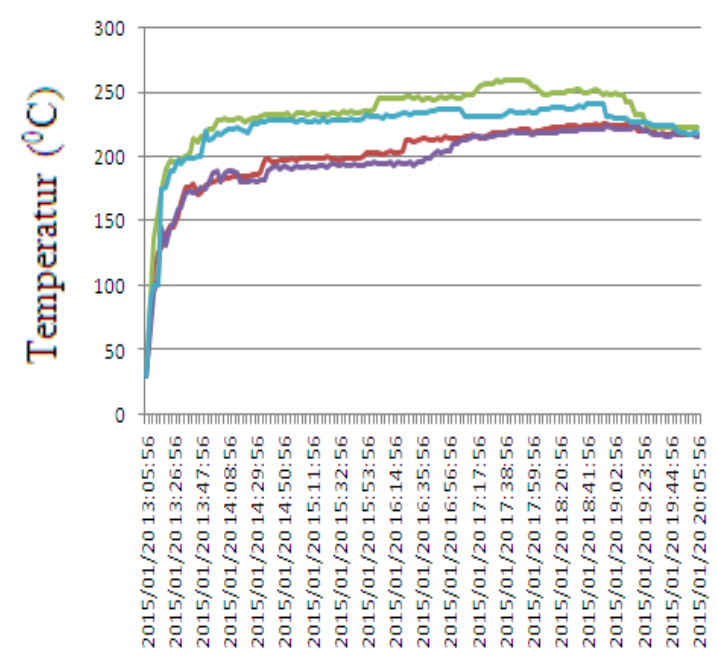

waktu 
Gambar 4.13 Grafik Temperatur vs Waktu Desorpsi Alat Penguji Adsorpsi (metanol) menggunakan baut.

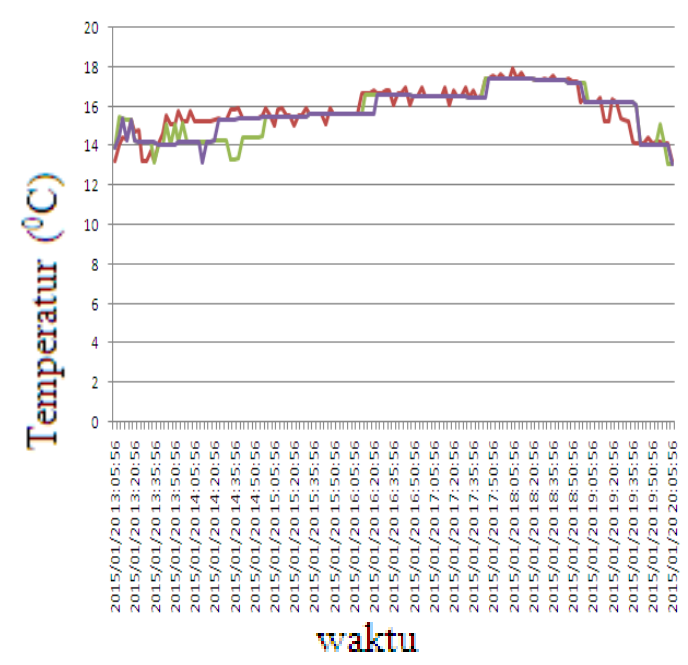

Gambar 4.14 Grafik Temperatur vs Waktu Desorpsi Gelas Ukur Refrigerant (metanol)

Pada pengujian. pada gelas ukur dapat dilihat jumlah volume metanol yang kembali pada proses desorpsi. Volume metanol yang kembali setelah dilakukan pemanas dari pukul 13.05 WIB sampai dengan jam 20.05 WIB ke gelas ukur adalah sebanyak $350 \mathrm{~mL}$.

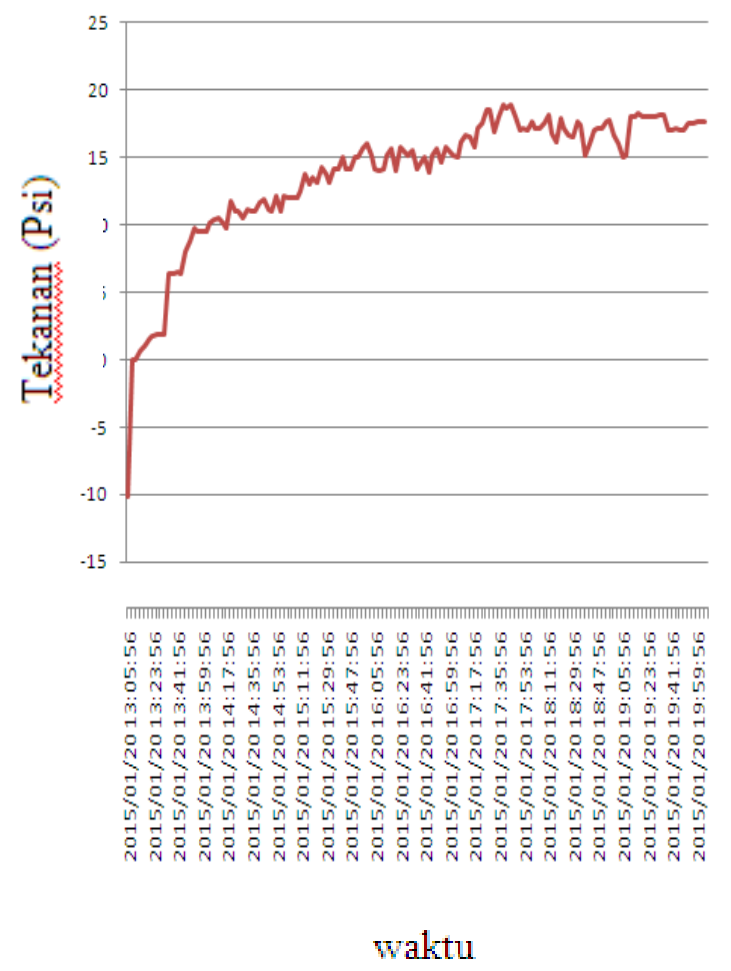

Gambar 4.15 Grafik Tekana vs Waktu 

17.38 .

Tekanan maximum yang dapat dicapai pada desorpsi yaitu 18,95 Psi pada pukul

\section{Adsorber Tanpa Menggunakan Baut}

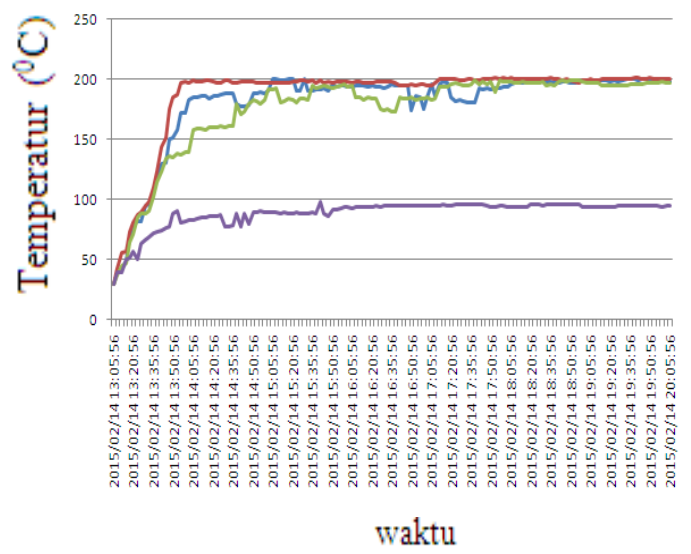

Gambar 4.16 Grafik Temperatur vs Waktu Desorpsi Alat Penguji Adsorpsi (metanol) tanpa menggunakan Baut

Temperatur maksimum yang dapat dicapai pada adsorber ketika dilakukan pemanasan adalah $201,9^{\circ} \mathrm{C}$ pada pukul 19.38 WIB.

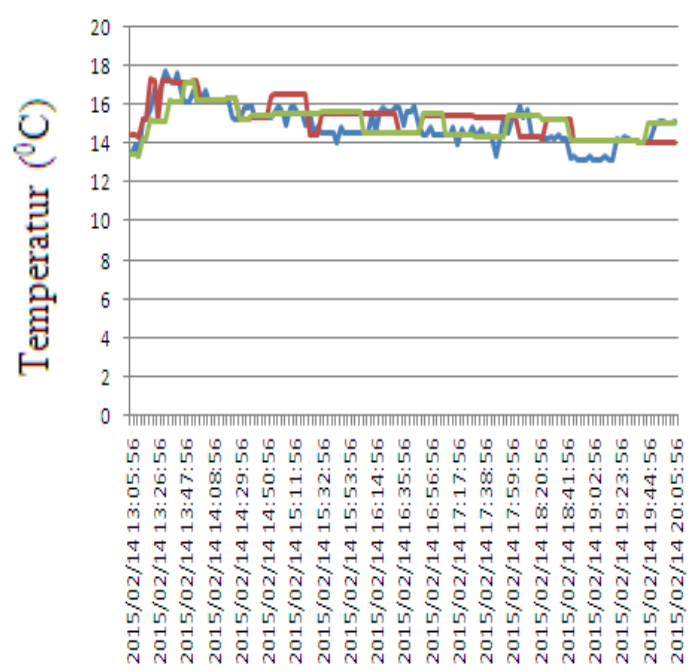

waktu

Gambar 4.18 Grafik Temperatur vs Waktu Desorpsi Gelas Ukur Refrigerant (metanol)

Volume metanol yang kembali setelah dilakukan pemanas dari pukul 13.05 WIB sampai dengan jam 20.05 WIB ke gelas ukur adalah sebanyak $275 \mathrm{~mL}$. 


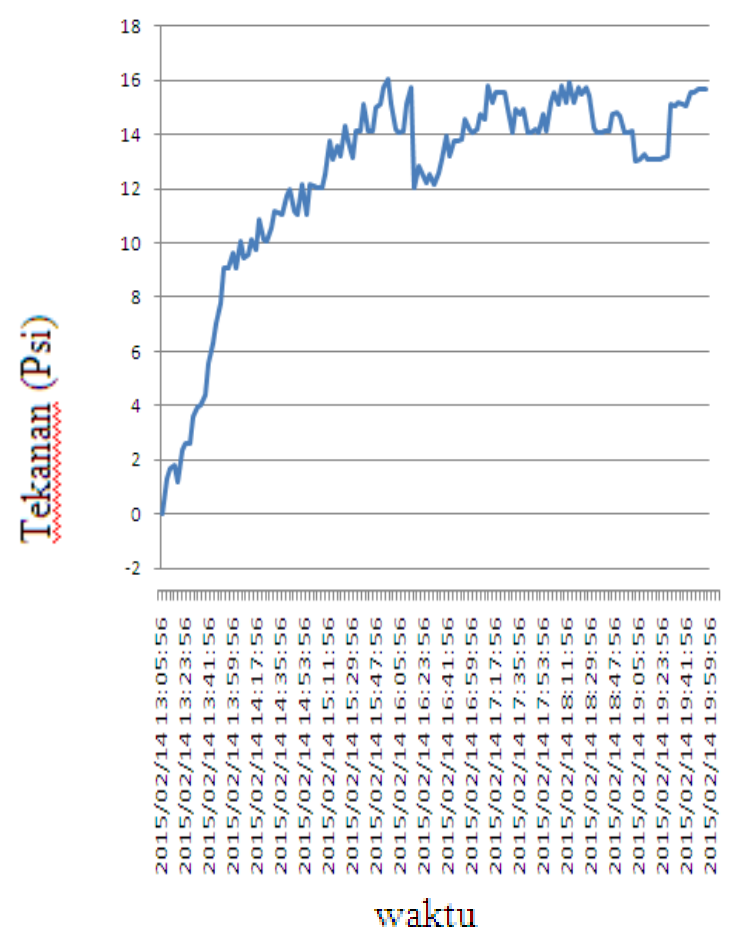

Gambar 4.19 Grafik Tekana vs Waktu

Tekanan maximum yang dapat dicapai pada desorpsi yaitu 16,04 Psi pada pukul 15.47 WIB.

\section{Kesimpulan}

Dari hasil penelitian dapat diperoleh kesimpulan sebagai berikut ini.

1. Energi adsorpsi dari karbon aktif selama proses adsorpsi pada pengujian masingmasing refrigeran berlangsung selama 17 jam (mulai jam 20.05 WIB sampai dengan pukul 13.05 WIB pada keesokan harinya).

- Karbon Aktif dengan adsorber menggunakan baut energy adsorpsinya adalah $510,48 \mathrm{~J} / \mathrm{mol}$

- Karbon Aktif dengan adsorber tidak menggunakan baut energy adsorpsinya adalah $371,55 \mathrm{~J} / \mathrm{mol}$

2. Adsorpsi pada pengujian masing-masing refrigeran berlangsung selama 17 jam (mulai jam 20.05 WIB sampai dengan pukul 13.05 WIB pada keesokan harinya).

Desorpsi pada pengujian masing-masing refrigeran berlangsung selama 8 jam (mulai pukul 13.05 WIB sampai dengan pukul 20.05 WIB). hasil/data dari proses adsorpsi dan desorpsi dengan gelas ukur diisolasi dengan styrofoam:

a. Volume refrigeran metanol yang dapat diserap (adsorpsi) sama dengan volume refrigeran metanol yang didesorpsi dari karbon aktif dengan menggunakan baut yaitu sebesar $350 \mathrm{~mL}$. 
b. Volume refrigeran metanol yang dapat diserap (adsorpsi) sama dengan volume refrigeran metanol yang didesorpsi dari karbon aktif dengan tanpa baut yaitu sebesar $275 \mathrm{~mL}$.

3. Efisiensi kolektor

a. Efisiensi kolektor dengan menggunakan baut $\mathbf{4 8 , 2 4} \%$

b. Efisiensi kolektor tanpa menggunakan baut $\mathbf{3 2 , 9 2} \%$

4. Efisiensi Gelas Ukur, dengan kondisi gelas ukur diisolasi Styrofoam:

- Efisiensi gelas ukur dengan adsorber menggunakan baut $\mathbf{1 7 , 7 4 \%}$

- Efisiensi gelas ukur dengan adsorber tanpa baut 20,69 \%

5. Dalam percobaan ini jumlah refrigeran yang diserap lebih maksimal dari percobaan sebelumnya, hal ini dikarenakan penyerapan panas di dalam adsorber lebih maksimal karena adanya penggunaan baut.

\section{DAFTAR PUSTAKA}

1. Holman,J.P.,Perpindahan Panas, Penerbit Erlangga, Jakarta Pusat.

2. Sitorus T.B., Napitupulu F.H. \& Ambarita H. 2016. International Journal of Technology, IJTech Journal, Vol. 7 Issue 5, pp. 910-920.

3. Purba, Oloan., (2013), Pembuatan Alat Penguji Kapsitas Adsorpsi pada

Mesin Pendingin Adsorpsi Dengan Menggunakan Adsorben Karbon Aktif., Skripsi,

Fakultas Teknik, USU, Medan.

4. Tulus B. Sitorus, Farel H. Napitupulu, Himsar Ambarita. 2017. J. Eng. Technol. Sci., Vol. 49, No. 5, 657-670.

5. Wuntu, A.D dan Kamu, V.S., (2008),

6. Jurnal Kimia Online: Adsorpsi Aseton Benzena, dan Toluena pada Karbon Aktif Tempurung Kelapa Sebagai Pembersih Udara Ruang Tertutup : 66 - 67. 